\title{
Empirical study on innovation motivators and inhibitors of Internet of Things applications for industrial manufacturing enterprises
}

\author{
Timon B. Heinis ${ }^{1 *}$ (1D, Jan Hilario ${ }^{2}$ and Mirko Meboldt ${ }^{1}$
}

\footnotetext{
*Correspondence: tiheinis@ethz.ch 'ETH Zurich, Product Development Group Zurich, Leonhardstrasse 21, 8092 Zurich, Switzerland

Full list of author information is available at the end of the article
}

\begin{abstract}
Industrial manufacturing enterprises in export-oriented economies rely on product or service innovation to maintain their competitive advantage. Decreasing costs of computing power, connectivity and electronic components have facilitated a wide range of innovations based on Internet of Things (loT) applications. However, only few successful loT applications specific to industrial manufacturing enterprises are known. Although academics have been investigating challenges related to realising loT, existing literature does not explain this situation integrally. Therefore, interest and engagement in and motivators and inhibitors of loT application development and deployment are investigated based on a literature review and empirically based on a survey with $N=109$ participants from enterprises in the Swiss metal, electrical and machine industries. Most enterprises are interested and are often engaged in loT application development. Improving service and aftersales activities through loT applications is a common motivator. Inhibitors from four domains hinder the development of loT applications: business, organisational, technological and industrial. Business and organisational inhibitors are perceived to be more challenging than the technological and industrial ones. The business and organisational issues presented herein have essential impacts on the success of innovation in loT applications. The results indicate future research directions for the innovation and development of loT applications, and they can be used by organisations interested in loT-based innovations to refine policy and decision-making.
\end{abstract}

Keywords: Internet of things, Digitalisation, Industry survey, Innovation, Motivators, Inhibitors

\section{Background}

\section{Context}

The decreasing costs of computing power, connectivity and electronic components have facilitated the realisation of the vision of Internet of Things (IoT) and have created potential for all sorts of applications. Various media channels, the World Economic Forum (Schwab 2015) and academic researchers (Brynjolfsson and McAfee 2014) have claimed that a technology-driven revolution is underway that would change the way mankind lives and runs the economy. At the core of this revolution is the merger of physical and

(c) The Author(s). 2018 Open Access This article is distributed under the terms of the Creative Commons Attribution 4.0 International License (http://creativecommons.org/licenses/by/4.0/), which permits unrestricted use, distribution, and reproduction in any medium, provided you give appropriate credit to the original author(s) and the source, provide a link to the Creative Commons license, and indicate if changes were made. 
digital spaces as cyber-physical systems. "Cyber-physical systems (CPS) will transform how humans interact with and control the physical world" (Rajkumar et al. 2010). The term is defined as follows: "cyber-physical systems (CPS) are physical and engineered systems whose operations are monitored, coordinated, controlled and integrated by a computing and communication core" (Rajkumar et al. 2010). The communication capabilities of such systems drive the technological revolution because they allow multiple systems to be connected, thereby creating the IoT. The IoT paradigm is the result of the convergence of three perspectives: (1) thing-oriented, (2) Internet-oriented and (3) semantic-oriented (Atzori et al. 2010). In other words, physical things can be sensed or can sense data automatically (1). The data are then communicated automatically to other things or humans (2). The data are interpreted and evaluated automatically to derive meaning (3). These three perspectives help realise the vision of an Internet containing information about the physical world without depending on human input (Ashton 2009). Technological progress in the information and communication technology (ICT) domain has reduced the costs of computing power, connectivity and electronic components. This decrease has helped the IoT to become increasingly real and has created potential for a wide range of promising innovations. Unsurprisingly, there is a lot of hype about IoT (Burton and Walker 2015). Clearly, several IoT applications are appearing in domains such as smart homes, wearables and smart cities. Well-known IoT applications are often desirable consumer gadgets (e.g. colour-changing light balls or fitness trackers). Known applications with a positive economic or ecological impact remain scarce (e.g. parking or bin fill level monitoring) (SAS Institute Inc 2016). In industrial manufacturing enterprises of specialised and export-oriented economies, even fewer IoT-based innovations are known, despite the opportunities offered by various technological enablers. The question then is, what inhibits the development and deployment of IoT applications in industrial manufacturing enterprises and thus prevents potential innovations-missing motivation or existing inhibitors?

\section{Need}

Although the potential of IoT and the challenges associated with realising it have been reviewed and discussed conceptually (Saarikko et al. 2017; Russo et al. 2015; Lee and Lee 2015; Li et al. 2014; Perera et al. 2014; Khan et al. 2012), the literature does not cover well the motivators and inhibitors of IoT application development and deployment among industrial manufacturing enterprises. The scope of the key challenges identified is generic and valid for the entire IoT ecosystem-for example Naming and Identity Management (Khan et al. 2012) - but it might not be equally relevant for individual enterprises aiming to develop specific IoT applications. The existing theoretical work is based mainly on conceptual models and is not backed up by empirical data. Existing empirical works on digitalisation, the fourth industrial revolution and IoT do not or only partially cover interest, engagement, motivators and inhibitors of the development and deployment of IoT applications among industrial manufacturing enterprises (Table 1). Studies that do cover motivators and inhibitors do not focus specifically on IoT application development among industrial manufacturing enterprises (Geissbauer et al. 2016; Weiss et al. 2016); instead, they target all sorts of industries (Twentyman and Swabey 2015; SAS Institute Inc 2016) for example healthcare, retail and consumer goods-or they survey large enterprises (LEs) only. 


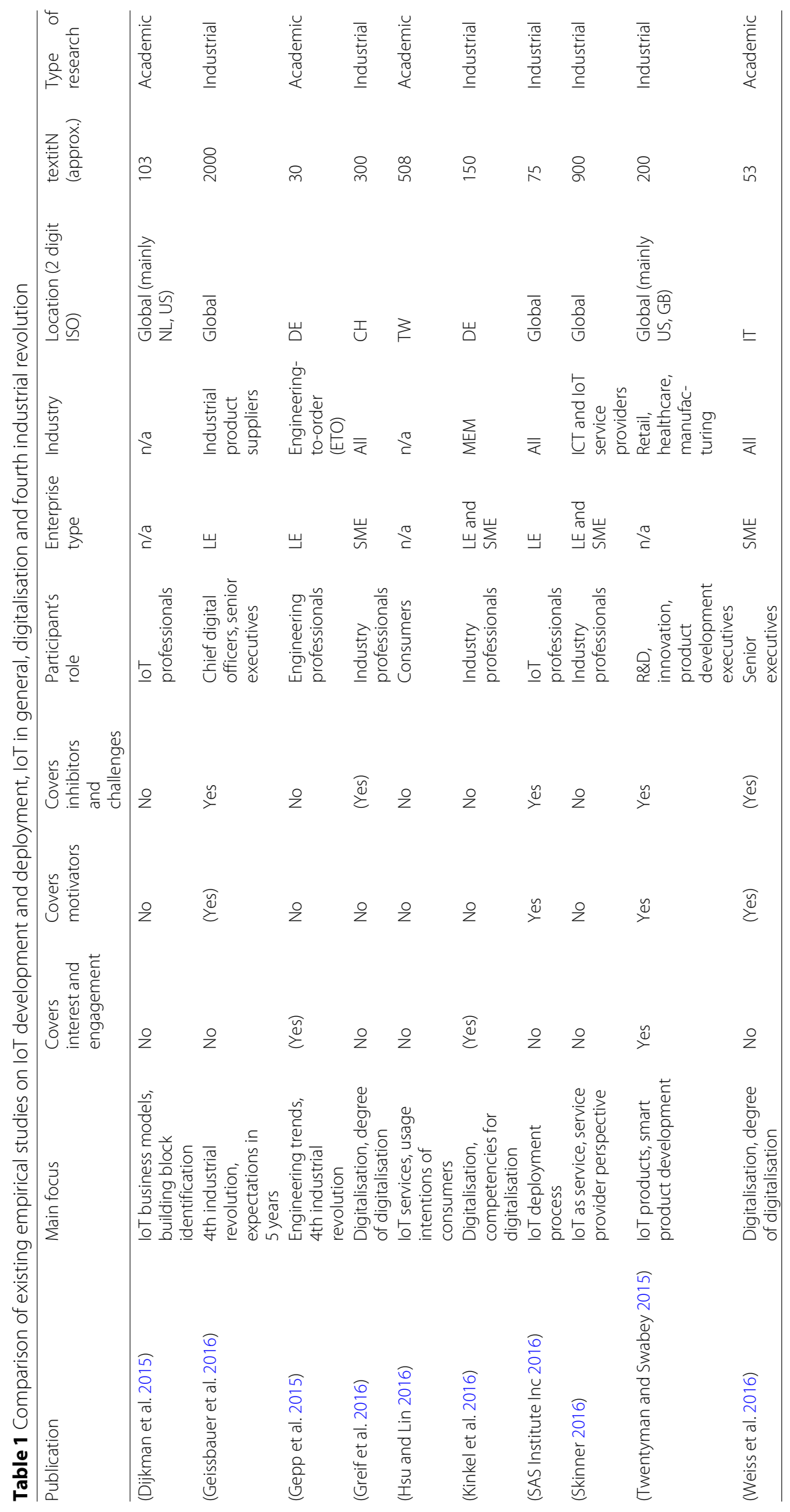


Small- and medium-sized enterprises (SMEs) with fewer than 250 employees have not surveyed in this regard, although the exports of high-wage economies are dominated by industrial manufacturing SMEs-for example, the Swiss metal, electrical and machine industries (MEM) are responsible for more than 30\% of the total goods exports, and the majority of the enterprises in these industries are SMEs (Swissmem 2016). Export-oriented industrial manufacturing enterprises rely on innovations to maintain their competitive advantage in current globalised markets (Kaleka 2002). Raymond et al. (2018) argued that information technology (IT) capabilities can be used for innovation purposes in industrial SMEs. Thus, IoT-based innovations can help achieve competitive advantages in globalised markets.

Studies in the literature do not exhaustively cover the motivators or inhibitors of IoTbased innovations but focus on a limited range of topics such as privacy issues or data analytics capabilities. By focusing on IoT products (smart products) only and excluding enterprise-internal IoT applications, Twentyman and Swabey (2015) analysed one perspective on IoT application development in depth but missed out on providing a holistic view. A holistic and consolidated study on the motivators and inhibitors of IoT application development from the perspective of manufacturing enterprises is needed to understand the entire system of technology-based innovations, such as access to technology, business and financial issues and research and development knowledge and skills. Only a holistic view of the system allows us to compare the relevance of individual motivators and inhibitors effectively, as well as to define measures that can foster IoT-based innovations in industrial manufacturing enterprises.

\section{Task}

The present study investigates the interests and engagement of industrial manufacturing enterprises in IoT-based innovations and aims to provide a holistic understanding of the motivators and inhibitors of innovation in IoT application development and deployment in these enterprises. This knowledge is necessary to refine policy and decision-making in governments or industry associations interested in fostering IoT-based innovations or in enterprises operating and innovating in the era of technology-driven digital transformation. The authors address three specific research questions (RQ). They investigate (1) interest and engagement in, (2) motivators and (3) inhibitors of development and deployment of IoT applications in industrial manufacturing enterprises by presenting two conceptual models based on a literature review-one on motivators and one on inhibitors-and empirical data from a survey with 109 participants from Swiss MEM industries.

1 RQ1. Are manufacturing enterprises interested and engaged in the development and deployment of IoT applications?

2 RQ2. What benefit (added value) do enterprises expect from the development and deployment of IoT applications?

3 RQ3. Which inhibitors hinder the development and deployment of IoT applications?

\section{Interest and engagement (RQ1)}

The first RQ targets the interest and engagement in the development and deployment of IoT applications. In relation to the first RQ, three hypotheses $(\mathrm{H})$ can be formulated. These hypotheses claim differences in interest and engagement based on the type of 
enterprise (SME or LE) and based on the importance rating of manufactured products integrated into an IoT application (digitalised products). Developing and deploying IoT applications is a form of innovation. Heck (2017) discussed the characteristics relevant to the innovation capabilities of SMEs, which differ from those of LEs. These differences allowed us to hypothesise different interests and levels of engagement in IoT application development and deployment for SMEs and LEs.

- H1a. Importance of digitalised products is rated differently depending on the type of enterprise.

- H1b. Level of engagement in IoT application development and deployment differs depending on the type of enterprise.

- H1c. Enterprises that assign more importance to digitalised products are more likely to engage in the development of IoT applications.

\section{Motivators (RQ2)}

The second RQ targets the reasons and motivators for the development and deployment of IoT applications. A conceptual model is needed to holistically collect and map the motivators driving the development and deployment of IoT applications. Thus, the first step to answering RQ2 would be the development of a conceptual model capturing motivators (RQ2a). The differences between SMEs and LEs allow us to hypothesise different motivators for different enterprise types (H2a). Furthermore, engaged enterprises may have different motivators than non-engaged enterprises $(\mathrm{H} 2 \mathrm{~b})$.

- RQ2a. Which conceptual model allows us to holistically collect and map motivators?

- H2a. SMEs and LEs rate the importance of motivators differently.

- H2b. Engaged enterprises and non-engaged enterprises rate the importance of motivators differently.

\section{Inhibitors (RQ3)}

The third RQ targets the inhibitors and challenges associated with the development and deployment of IoT applications. Inhibitors can be identified and collected from the literature on the topic. A conceptual model is needed to map the inhibitors exhaustively (RQ3a). Furthermore, inhibitors can be identified based on the statements of industry members (RQ3b). Not all inhibitors are expected to have the same significance (H3a).

- RQ3a. Which conceptual model allows us to holistically collect and map inhibitors?

- RQ3b. Which inhibitors are perceived by industrial manufacturing enterprises?

- H3a. Some inhibitors are perceived to be more challenging than the others.

\section{Results}

\section{Conceptual frameworks}

The term IoT application as used in this study is defined in this section. In addition, a literature review on motivators and inhibitors of the development and deployment of IoT applications and two resulting conceptual models are presented. An extended valuechain model for motivators and four domains of inhibitors emerged from the literature review. 


\section{Definition of loT application}

The term IoT application used in this study is defined based on three main elements: (1) physical object, (2) data processing functionality and (3) added value (Heinis et al. 2017). The second element contains three functional sub-elements: (2.1) data sensing, (2.2) data transmission and (2.3) data evaluation. This framework allows us to capture and describe IoT applications integrally, covering the technological, business, engineering design and innovation aspects.

\section{Motivators along value-chain}

A list of eight motivators $(\mathrm{m} 1-\mathrm{m} 8)$ related to the development and deployment of IoT applications, as well as the potential added value of IoT applications, emerged from the literature presented in the "Background" section (Table 2).

The extended value-chain model is introduced as a conceptual model that allows us to capture exhaustively the motivators of IoT application development (Fig. 1). In theory, enterprises conduct activities or investments only if they expect added economic value. This theory is true for engagement in IoT application development and deployment. Thus, by implication, expected added value underlies each motivator to develop or deploy IoT applications. The value-chain framework describes the activities conducted by an enterprise to generate value (Porter 1985). Added value is created within an enterprise by increasing the efficiency or effectiveness of value-chain activities or by defining new value-generating activities. Therefore, the value-chain model allows us to allocate the relevant enterprise-internal motivators of IoT application development and deployment. The traditional value-chain model proposed by Porter (1985) does not explicitly cover the creation of added value for enterprise customers. External motivators based on added value for the customer cannot be allocated. In the MEM industries, customers are typically other enterprises that use a product or service to create value for their downstream customers. The relevant activities for allocating potential external motivators are thus related to product or service usage. By extending the value-chain model with product or service usage activities according to the ideas of McPhee and Wheeler (2006), potential internal or external IoT applications can be identified.

\section{Inhibitors in four domains}

A conceptual model consisting of four domains of inhibitors allowed us to cluster into four domains the wide range of inhibitors of IoT application development and deployment

Table 2 Possible motivators of development and deployment of loT applications presented to

\begin{tabular}{ll} 
survey participants for selection \\
\hline Motivator ID & Motivators \\
\hline $\mathrm{m} 1$ & Offer shared products and services as an alternative to individual ownership \\
m3 & Use collected data to improve decision-making \\
m4 & Gain revenues through new or different business models \\
m5 & Improve manufacturing and production process \\
m6 & Enhance market research for better customer segmentation or pricing strategies \\
m7 & Monitor product state and usage for predictive maintenance and repair \\
m8 & Assess product usage and performance to improve product design and development \\
mOT & Track product location to improve logistics \\
\hline
\end{tabular}




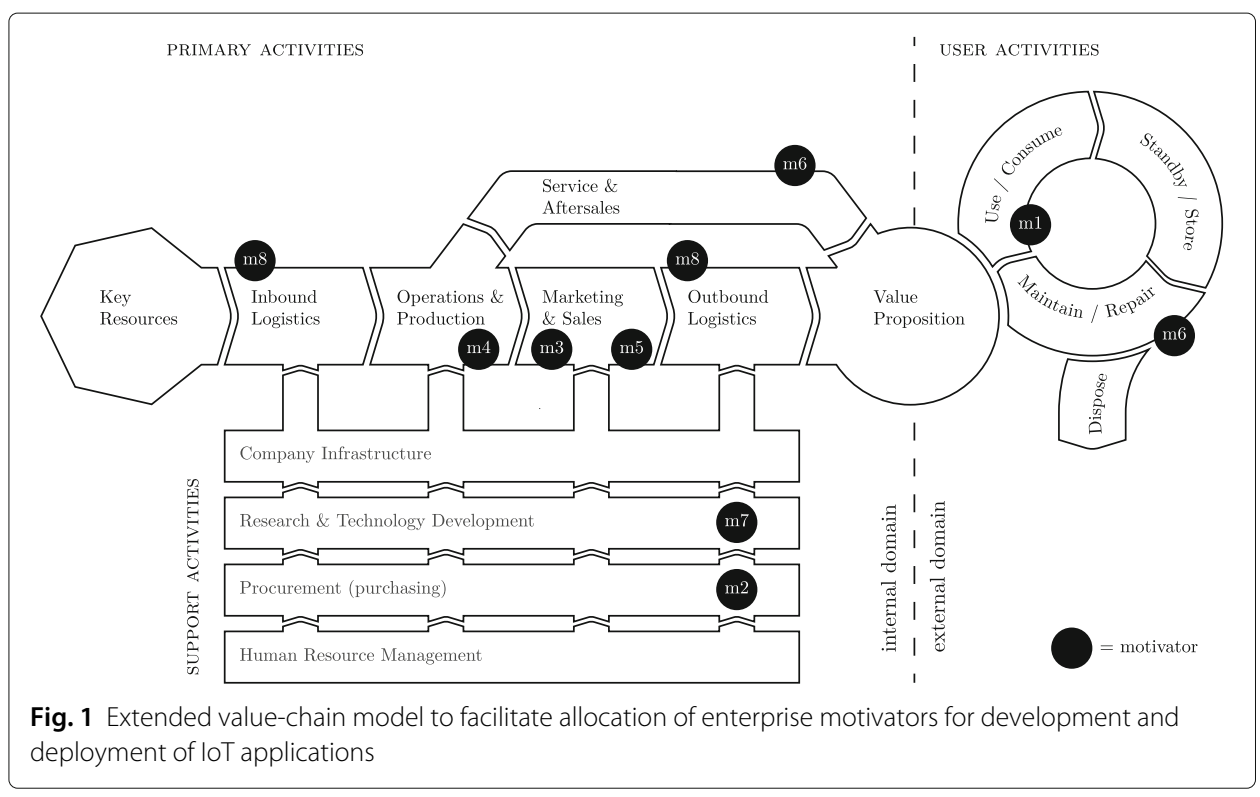

identified in literature: organisational, business, technological and industrial (Table 3). The model helps cover a wide range aspects of technology-based innovations.

Organisational domain Seven unique inhibitors (o1-o7) belonging to the organisational domain were identified in the literature (Table 3). Geissbauer et al. (2016) reported a lack of clear vision and strategy for digital operations and a lack of leadership from top management as important inhibitors. An unsuitable organisational structure or missing key functional areas were identified as inhibitors by Porter and Heppelmann (2015) and by Twentyman and Swabey (2015). A non-existent digital culture and lack of training were mentioned as inhibitors in multiple studies (Geissbauer et al. 2016; SAS Institute Inc 2016; Twentyman and Swabey 2015). Another inhibitor mentioned in multiple sources is the lack of in-house expertise or skills (Geissbauer et al. 2016; Porter and Heppelmann 2015; Curran et al. 2015; Twentyman and Swabey 2015). Pech (2016) stated that the adoption of disruptive technologies decelerates when special training is involved. Data analytics capabilities is a more specific but indispensable skill (Geissbauer et al. 2016). Integration between physical product development and software development processes is essential for the development of IoT applications. This can be difficult when product design and engineering occur over a lengthy, linear development cycle, as opposed to digital and software design, which proceed in short, modular development loops (Hui 2014).

Business domain Seven unique inhibitors (b1-b7) belonging to the business domain were identified in the literature (Table 3). Expectations related to the impact of IoT applications on demand and revenues are contradictory (Twentyman and Swabey 2015). The same applies to the expected impact on cost: decrease (Geissbauer et al. 2016) versus increase (Twentyman and Swabey 2015). There is considerable uncertainty around revenues and costs. This could inhibit enterprises from deploying IoT applications because of the higher perceived risk and volatility of IoT investments. Enterprises face challenges 
Table 3 Conceptual model covering inhibitors of development and deployment of loT applications

\begin{tabular}{|c|c|}
\hline Inhibitor ID & Organisational inhibitor \\
\hline 01 & Lack of clear digital operations vision/strategy \\
\hline 02 & Unsuitable organisational structure or missing key functional areas \\
\hline 03 & Lack of leadership from top management \\
\hline 04 & Lack of digital culture and training \\
\hline 05 & Lack of in-house expertise or skills \\
\hline 06 & Lack of capabilities in data analytics \\
\hline 07 & Lack of integration between physical product development and software development \\
\hline oNA & Not applicable \\
\hline Inhibitor ID & Business inhibitor \\
\hline b1 & Insufficient information to predict demand and revenues, resulting in high uncertainty \\
\hline b2 & Weak value proposition of loT applications and resulting low customer demand \\
\hline b3 & Difficulty in identifying market opportunities \\
\hline b4 & Insufficient information to predict costs or required investment \\
\hline b5 & Issues related to monetisation under current business model \\
\hline b6 & Issues related to collaboration with suppliers or partners on digital solutions \\
\hline b7 & Issues related to choosing level of vertical integration for loT applications \\
\hline bNA & Not applicable \\
\hline Inhibitor ID & Technological inhibitor \\
\hline t1 & Availability of basic infrastructure technologies \\
\hline t2 & Difficulties related to selecting enabling technologies to realise loT applications \\
\hline t3 & Difficulties related to interoperability with internal or external systems \\
\hline t4 & Need for standardised identification and addressing protocols \\
\hline t5 & Internet scalability to handle increase in traffic and requests \\
\hline t6 & Issues related to physical product design measures to prevent unauthorised data access \\
\hline t7 & Issues related to software measures to prevent unauthorised data access \\
\hline t8 & Insufficient tools to manage user authentication process \\
\hline t9 & Difficulties related to integration of digital components into physical product \\
\hline $\mathrm{t} 10$ & Access to tools and database to handle big data \\
\hline tNA & Not applicable \\
\hline Inhibitor ID & Industrial inhibitor \\
\hline ¡1 & Undefined regulations and laws around customer privacy and data collection \\
\hline$i 2$ & Undefined regulations and laws around the use and sharing of data \\
\hline i3 & Lack of comprehensive and widely accepted service intermediaries \\
\hline i4 & Lack of certification to improve trust among customers and industry participants \\
\hline i5 & Potential loss of intellectual property \\
\hline iNA & Not applicable \\
\hline
\end{tabular}

in terms of identifying market opportunities, establishing appropriate channels, defining the value proposition of IoT applications and handling the new demands associated with a closer customer relationship (Porter and Heppelmann 2015; Fleisch et al. 2015; SAS Institute Inc 2016; Twentyman and Swabey 2015). Fleisch et al. (2015) reported that IoT changes existing business models. The business model of an industrial manufacturing enterprise is usually based on product sales, and service-oriented business models are rare (Adrodegari et al. 2014). Enterprises thus face issues with monetisation, for example, of data under current business models (Tobler et al. 2013). Enterprises face issues in terms of collaborating with suppliers or partners on digital solutions. Missing digital expertise 
forces industrial manufacturing enterprises to collaborate with new suppliers and partners. The bargaining power of these suppliers can be high, thus allowing them to capture a large share of the IoT applications' value (Porter and Heppelmann 2014). Developing IoT applications can expand the range of activities of an enterprise, which is necessary to create value. Given the broad range and complexity of activities and limited resources, SMEs, especially, may face challenges in terms of choosing the level of vertical integration to develop IoT applications.

Technological domain Ten inhibitors (t1-t10) can be assigned to the technological domain (Table 3). As mechanical parts are replaced with software, the physical complexity of a product usually diminishes (Porter and Heppelmann 2015). IoT applications may have fewer physical components, but the number of sensors required and the pervasiveness of software use rise. These requirements create new challenges for industrial manufacturing enterprises because digital components must be integrated in physical products. Several studies have explored open issues related to middleware or architecture for IoT (Atzori et al. 2010; Bandyopadhyay and Sen 2011; Khan et al. 2012) that impede IoT deployment. Given the complexity of IoT middleware, industrial manufacturing enterprises face the challenge of identifying the appropriate architecture and selecting enabling technologies. The sheer volume of data available from IoT applications and the business impacts of its use go hand-in-hand with the challenges pertaining to handling and analysing data (Gubbi et al. 2013; Lee and Lee 2015). In addition, the integration of IoT applications with existing internal or external software systems necessary to create a lasting business impact is challenging. The complexity and availability of infrastructure technologies can pose a significant challenge for industrial manufacturing enterprises. Essential connectivity requirements include internet scalability and the need for standardisation to connect and integrate technologies (Bandyopadhyay and Sen 2011, Atzori et al.2010, Porter and Heppelmann 2015). Additional technological inhibitors are based on the implementation of hardware or software measures to prevent any unauthorised data access. Atzori et al. (2010) outlined the various reasons why IoT applications are especially vulnerable to attacks. First, the physical components of an IoT application are mostly exposed and unattended, and it is difficult to protect them with physical measures. Second, communication is often wireless, which arguably makes it easy for unauthorised persons to intercept them. Last, IoT components cannot implement complex schemes to support security because they typically have limited energy and computing resources.

Industrial domain Five inhibitors (i1-i5) belonging to the industrial domain were identified in literature (Table 3). These inhibitors affect the industry overall and are largely external to the enterprise. The lack of clear regulations on the collection, sharing and use of data can pose significant legal challenges for enterprises developing IoT applications. Issues pertaining to data access and collection are tied to the basic right to privacy, which includes concealing personal information and the ability to control what happens with this information (Weber 2010). IoT applications will remain limited to a few niche markets if there is continued public concern about privacy (Sundmaeker et al. 2010). The lack of comprehensive, trustworthy and widely accepted service intermediaries prevents the 
deployment of IoT applications (Haller et al. 2009). The lack of a method for certification of IoT applications can pose a challenge to enterprises trying to establish credibility and improve customer trust in their IoT applications. A few emerging certification programs for IoT-specific applications are available (Underwriters Laboratories 2016; ICSA Labs 2017; IoT Security Foundation 2017). However, these certification programs are in the early stages of development, and they may not have a significant impact on the market acceptance of IoT applications. Data ownership and intellectual property issues within the IoT domain are important and widely discussed topics which could inhibit enterprises from developing IoT applications (Porter and Heppelmann 2014; Geissbauer et al. 2016).

\section{Empirical evidence}

This section presents the results of our survey and statistical evaluation of the gathered data in three subsections, one each on (1) interest and engagement, (2) motivators and (3) inhibitors.

\section{Interest and engagement}

Survey respondents from SMEs are not more likely to rate the importance of digitalised products differently than LEs, even though the values for each category differ (Table 4). The null hypothesis corresponding to $\mathrm{H} 1 \mathrm{a}$ is not rejected. There is no significant difference between SMEs and LEs (Mann-Whitney $U=1176.5, p=0.075, \alpha=0.05$, two tailed).

Survey respondents from SMEs are more likely to not engage in IoT application development. The results do not contradict hypothesis H1b. Two chi-square tests of independence were performed to examine the relationship between enterprise type and the level of interest and engagement. The level of interest and engagement in IoT application development is one categorical dependent variable, and it is measured based on the selection of five possible answers (no plans and no interest, no plans but interest, plans, in progress, experienced) (Table 5). The relationship between enterprise type and level of interest and engagement is significant, $\chi^{2}(4, N=109)=11.45^{*}, \alpha=.05, p=0.0219$. A second dependent variable can be obtained by dividing the participants into two groups (non-engaged, engaged) based on their levels of interest and engagement (Table 6). Participants who selected in progress or experienced were assigned to the engaged group, and the rest were assigned to the non-engaged group. The relationship between enterprise type and level of interest and engagement based on the two groups is very significant, $\chi^{2}$ $(1, N=109)=7.85^{* *}, \alpha=.01, p=0.00508$.

Survey respondents who assigned higher importance to digitalised products are more likely to engage in the development and deployment of IoT applications. These results do not contradict hypothesis H1c. Again, two chi-square tests of independence were performed to examine the relationship between the importance of digitalised products and the level of interest and engagement. The two dependent variables describing the level of

Table 4 Importance of digitalised products separated by type of enterprise

\begin{tabular}{llllll}
\hline Enterprise type & $N$ & Not important (\%) & Somewhat important (\%) & Important (\%) & Very important (\%) \\
\hline SME & 60 & 8 & 25 & 32 & 35 \\
LE & 49 & 0 & 12 & 45 & 43 \\
All & 109 & 5 & 19 & 38 & 39 \\
\hline
\end{tabular}


Table 5 Interest and engagement in developing loT applications separated by enterprise type

\begin{tabular}{lllllll}
\hline Enterprise type & $N$ & $\begin{array}{l}\text { No plans and } \\
\text { no interest (\%) }\end{array}$ & $\begin{array}{l}\text { No plans but } \\
\text { interest (\%) }\end{array}$ & Plans (\%) & In progress (\%) & Experienced (\%) \\
\hline SME & 60 & 28 & 12 & 22 & 15 & 23 \\
LE & 49 & 6 & 10 & 18 & 29 & 37 \\
All & 109 & 18 & 11 & 20 & 21 & 29 \\
\hline
\end{tabular}

interest and engagement used to test $\mathrm{H} 1 \mathrm{~b}$ were used to test $\mathrm{H} 1 \mathrm{c}$ as well. The relationship between the importance of digitalised products and the level of interest and engagement is significant, $\chi^{2}(12, N=109)=24.73^{*}, \alpha=.05, p=0.0162$ (Table 7). The relationship between the importance of digitalised products and the level of interest and engagement based on the two groups is very significant, $\chi^{2}(3, N=109)=11.96^{* *}, \alpha=.01$, $p=0.00751$ (Table 8).

\section{Motivators}

In total, 91 statements extracted from the open-ended question on motivators and expected added value of IoT application development and deployment were coded and assigned to a value-chain activity (Table 9). Of these statements, 56\% (51) were assigned to the domain of primary activities. The highest number of statements was assigned to the marketing and sales activity segment $(26 \%, 24)$. Examples include the expectation of new business models, competitive advantage, strengthening of market position and better access to customer data. Other important activity segments are service and aftersales $(16 \%, 15)$ and operations and production $(11 \%, 10)$. Examples include predictive maintenance and improved manufacturing. In total, 31\% (28) of the statements exhibited strong customer or product user focus and were allocated to user activities. Not all statements could be assigned to one specific activity (e.g. use/consume, standby/store). Statements related to the entire domain of user activities were thus assigned to all three activities, but with a weight of one third only (e.g. increased customer benefit). Only 13\% (12) of the statements were assigned to support activities. Noteworthy is the motivation to use IoT applications for research and technology development $(8 \%, 7)$. Participants revealed that they expect to use the data generated by IoT applications to improve products or services.

Based on participants' selections, the top three motivators for developing IoT applications are (1) monitoring product state and usage for predictive maintenance and repair (m6, 69\%), (2) using collected data to improve decision-making (m2, 61\%) and (3) improving manufacturing and production processes $(\mathrm{m} 4,60 \%)$ (Table 10). On average, participants selected $M=3.74$ motivators ( $\mathrm{SD}=1.92)$. The number of motivators selected by participants does not depend either on enterprise type (SME, LE) or on engagement of an enterprise (not engaged, engaged).

There are significant relationships between enterprise type (SME, LE) and selection of the motivators $\mathrm{m} 2, \mathrm{~m} 3$ and $\mathrm{m} 7$. The relationship between enterprise type and selection of

Table 6 Engagement in loT application development separated by enterprise type

\begin{tabular}{llll}
\hline Enterprise type & $N$ & Non-engaged (\%) & Engaged (\%) \\
\hline SME & 60 & 62 & 38 \\
LE & 49 & 35 & 65 \\
All & 109 & 50 & 50 \\
\hline
\end{tabular}


Table 7 Relationship between importance of digitalised products and level of interest and engagement

\begin{tabular}{|c|c|c|c|c|c|c|}
\hline $\begin{array}{l}\text { Importance } \\
\text { of digitalised } \\
\text { products }\end{array}$ & $N$ & $\begin{array}{l}\text { No plans and } \\
\text { no interest (\%) }\end{array}$ & $\begin{array}{l}\text { No plans but } \\
\text { interest (\%) }\end{array}$ & Plans (\%) & In progress (\%) & Experienced (\%) \\
\hline Not important & 5 & 60 & 20 & 0 & 0 & 20 \\
\hline $\begin{array}{l}\text { Somewhat } \\
\text { important }\end{array}$ & 21 & 38 & 10 & 24 & 24 & 5 \\
\hline Important & 41 & 12 & 15 & 27 & 22 & 24 \\
\hline Very important & 42 & 10 & 7 & 14 & 21 & 48 \\
\hline All & 109 & 18 & 11 & 20 & 21 & 29 \\
\hline
\end{tabular}

$\mathrm{m} 2$ use collected data to improve decision-making is very significant, $\chi^{2}(1, N=109)=$ $9.7217^{* *}, p<.01$. LEs are more likely than SMEs to select $\mathrm{m} 2$. The relationship between enterprise type and selection of $\mathrm{m} 3$ gain revenues through new or different business models is significant, $\chi^{2}(1, N=109)=4.4793^{*}, p<.05$. LEs are more likely to select $\mathrm{m} 3$. The relationship between enterprise type and selection of $\mathrm{m} 7$ assess product usage and performance to improve product design and development is very significant, $\chi^{2}(1, N=$ $109)=7.1376^{* *}, p<.01$. Again, LEs are more likely to select $m 7$. For all other motivators, no significant difference was found between SMEs and LEs $(p>0.05)$ (Table 11).

There are significant relationships between the level of engagement of an enterprise (non-engaged, engaged) and selection of $\mathrm{m} 3$ and $\mathrm{m} 7$. The relationship between the level of engagement of an enterprise and selection of $\mathrm{m} 3$ gain revenues through new or different business models is significant, $\chi^{2}(1, N=109)=5.736^{*}, p<.05$. Engaged enterprises are more likely to select $\mathrm{m} 3$ than non-engaged enterprises. The relationship between enterprise type and selection of $\mathrm{m} 7$ assess product usage and performance to improve product design and development is very significant, $\chi^{2}(1, N=109)=7.940^{* *}, p<.01$. Again, engaged enterprises are more likely to select $\mathrm{m} 7$ than non-engaged enterprises. For all other motivators, no significant differences were found between engaged and non-engaged enterprises (Table 12).

\section{Inhibitors}

An open-ended question before the closed-ended questions on inhibitors was included in the survey to determine the key inhibitors before presenting our response options. In total, 120 statements were collected and coded into the four inhibitor domains (Table 13). A total of $37.6 \%$ of respondents indicated an inhibitor that fit into the business domain. Common responses included the weak value proposition of IoT applications and issues with the existing business model. After the business domain, $26.4 \%$ of the collected statements were related to technological inhibitors. Statements covering organisational or industrial inhibitors were the least represented at $21.6 \%$ and $14.4 \%$ of the responses,

Table 8 Relationship between importance of digitalised products and level of engagement

\begin{tabular}{llll}
\hline Importance digitalised products & N & Non-engaged (\%) & Engaged (\%) \\
\hline Not important & 5 & 80 & 20 \\
Somewhat important & 21 & 71 & 29 \\
Important & 41 & 54 & 46 \\
Very important & 42 & 31 & 69 \\
All & 109 & 50 & 50 \\
\hline
\end{tabular}


Table 9 Assignment of statements from open-ended question on motivators and expected added value of IoT application development to value-chain activities

\begin{tabular}{llllll}
\hline Activity domain & \# statements & $\%$ statements & Value-adding activities & \# statements & $\%$ statements \\
\hline Primary activities & 51 & $56 \%$ & Inbound logistics & 1 & $1 \%$ \\
& & & Operations and production & 10 & $11 \%$ \\
& & & Service and aftersales & 15 & $16 \%$ \\
& & & Outbound logistics & 1 & $1 \%$ \\
Support activities & 12 & \multirow{2}{*}{$13 \%$} & Marketing and sales & 24 & $26 \%$ \\
& & & Company infrastructure & 1 & $1 \%$ \\
& & & R\&D development & 7 & $8 \%$ \\
User activities & 28 & & Procurement (purchase) & 2 & $2 \%$ \\
& & & Human resource management & 2 & $2 \%$ \\
Total & & & Use/consume & 10 & $11 \%$ \\
\hline
\end{tabular}

respectively. Inhibitors identified in response to this question have largely been covered in the response options. Other commonly cited inhibitors include a lack of knowledge, data security and regulatory issues.

With a weighted score of 267 , the business domain is the most important domain of challenges. The organisational domain is the second most challenging with a score of 235, followed by the technological domain with a score of 198. The industrial domain ranked the last with a score of 190. The differences in the ranking of the domains are highly significant (Friedman test: $\left.\chi^{2}(3, N=89)=25.57^{* * *}, p<0.001\right)$ (Table 14). Even though the ranking and the relative ranking scores of SMEs and LEs deviate from the ranking of all enterprises, a chi-square test did not show any significant differences in the selection of rankings depending on the enterprise type (SME or LE).

In the domain of organisational inhibitors, the top three inhibitors are based on the weighted score: (1) lack of clear digital operations vision/strategy with a score of 377, (2) lack of in-house expertise or skills with a score of 309 and (3) lack of integration between physical product development and software development processes with a score of 231 (Table 15). The differences in the ranking of the inhibitors are highly significant (Friedman test: $\left.\chi^{2}(7, N=89)=52.16^{* * *}, p<0.001\right)$.

Table 10 Ranking of motivators for loT application development and deployment based on selection frequency

\begin{tabular}{llll}
\hline Rank & Motivator ID & \# selections & $\%$ of $N=109$ \\
\hline 1st & m6 & 75 & $69 \%$ \\
2nd & m2 & 67 & $61 \%$ \\
3rd & m4 & 65 & $60 \%$ \\
4th & m3 & 59 & $54 \%$ \\
5 th & m7 & 47 & $43 \%$ \\
6th & m5 & 29 & $27 \%$ \\
7th & m1 & 28 & $26 \%$ \\
8th & m8 & 27 & $25 \%$ \\
9th & mOT & 11 & $10 \%$ \\
\hline
\end{tabular}


Table 11 Comparison of ranking of motivators for loT application development and deployment for SMEs and LEs based on selection frequency

\begin{tabular}{|c|c|c|c|c|c|c|c|c|c|c|}
\hline \multicolumn{2}{|l|}{ SMES } & \multirow{2}{*}{$\begin{array}{l}=60 \\
\# \\
\text { selections }\end{array}$} & \multirow{2}{*}{$\begin{array}{l}55 \% \\
\% \text { of } N\end{array}$} & \multicolumn{2}{|l|}{ LES } & \multirow{2}{*}{$\begin{array}{l}N=49 \\
\# \\
\text { selections }\end{array}$} & \multirow{2}{*}{$\frac{45 \%}{\% \text { of }}$} & \multicolumn{3}{|c|}{ Compared } \\
\hline Rank & $\begin{array}{l}\text { Motivator } \\
\text { ID }\end{array}$ & & & Rank & $\begin{array}{l}\text { Motivator } \\
\text { ID }\end{array}$ & & & Delta \% & $\begin{array}{l}\text { Chi-square } \\
(1, N=109)\end{array}$ & Significance \\
\hline 6th & $\mathrm{m} 1$ & 17 & $28 \%$ & 8th & $\mathrm{m} 1$ & 11 & $22 \%$ & $-6 \%$ & 0.489 & \\
\hline $3 r d$ & $\mathrm{~m} 2$ & 29 & $48 \%$ & $1 \mathrm{st}$ & $\mathrm{m} 2$ & 38 & $78 \%$ & $29 \%$ & 9.722 & $* *$ \\
\hline 4 th & m3 & 27 & $45 \%$ & $3 r d$ & m3 & 32 & $65 \%$ & $20 \%$ & 4.479 & * \\
\hline $1 \mathrm{st}$ & m4 & 40 & $67 \%$ & 5 th & m4 & 25 & $51 \%$ & $-16 \%$ & 2.743 & \\
\hline 7 th & m5 & 16 & $27 \%$ & 6th & m5 & 13 & $27 \%$ & $0 \%$ & 0.000 & \\
\hline 2nd & m6 & 39 & $65 \%$ & 2nd & m6 & 36 & $73 \%$ & $8 \%$ & 0.901 & \\
\hline 5 th & m7 & 19 & $32 \%$ & 4th & m7 & 28 & $57 \%$ & $25 \%$ & 7.138 & $* *$ \\
\hline 8th & m8 & 15 & $25 \%$ & 7 th & m8 & 12 & $24 \%$ & $-1 \%$ & 0.004 & \\
\hline 9th & mOT & 8 & $13 \%$ & 9th & mOT & 3 & $6 \%$ & $-7 \%$ & 1.546 & \\
\hline
\end{tabular}

In the domain of business inhibitors, the top three inhibitors are based on the weighted score: (1) insufficient information to predict demand and revenues, resulting in high uncertainty with a score of 265 ; (2) issues related to monetisation under current business model with a score of 261; and (3) difficulty in identifying market opportunities with a score of 224 (Table 15). The differences in the ranking of the inhibitors are very significant (Friedman test: $\left.\chi^{2}(7, N=89)=24.28^{* *}, p<0.01\right)$.

In the domain of technological inhibitors, the top three inhibitors are based on the weighted score: (1) difficulties related to interoperability with internal or external systems with a score of 385, (2) difficulties in selecting enabling technologies to realise IoT applications with a score of 351 and (3) availability of basic infrastructure technologies with a score of 320 (Table 15). The differences in the ranking of the inhibitors are highly significant (Friedman test: $\left.\chi^{2}(10, N=89)=41.55^{* * *}, p<0.001\right)$.

In the domain of industrial inhibitors, the top three inhibitors are based on the weighted score: (1) undefined regulations and laws around customer privacy and the collection of data with a score of 230, (2) undefined regulations and laws around the use and sharing of data with a score of 175 and (3) potential loss of intellectual property with a score of 159 (Table 15). The differences in the ranking of the inhibitors are very significant (Friedman test: $\left.\chi^{2}(5, N=89)=19.95^{* *}, p<0.01\right)$.

Table 12 Comparison of ranking of motivators for loT application development and deployment for non-engaged and engaged enterprises based on selection frequency

\begin{tabular}{|c|c|c|c|c|c|c|c|c|c|c|}
\hline \multicolumn{2}{|c|}{$\begin{array}{l}\text { Non- } \\
\text { engaged }\end{array}$} & \multirow{2}{*}{$\begin{array}{l}N=54 \\
\# \\
\text { selections }\end{array}$} & \multirow{2}{*}{$\frac{50 \%}{\% \text { of } N}$} & \multicolumn{2}{|l|}{ Engaged } & $N=55$ & \multirow{2}{*}{$\begin{array}{l}50 \% \\
\% \text { of } N\end{array}$} & \multicolumn{3}{|c|}{ Compared } \\
\hline Rank & $\begin{array}{l}\text { Motivator } \\
\text { ID }\end{array}$ & & & Rank & $\begin{array}{l}\text { Motivator } \\
\text { ID }\end{array}$ & $\begin{array}{l}\# \\
\text { selections }\end{array}$ & & $\begin{array}{l}\text { Delta } \\
\%\end{array}$ & $\begin{array}{l}\text { Chi-square } \\
(1, N=109)\end{array}$ & Significance \\
\hline 7 th & $\mathrm{m} 1$ & 12 & $22 \%$ & 7 th & $\mathrm{m} 1$ & 16 & $29 \%$ & $7 \%$ & 0.673 & \\
\hline $3 r d$ & $\mathrm{~m} 2$ & 31 & $57 \%$ & $2 \mathrm{nd} / 3 \mathrm{rd}$ & $\mathrm{m} 2$ & 36 & $65 \%$ & $8 \%$ & 0.745 & \\
\hline 4 th & m3 & 23 & $43 \%$ & $2 \mathrm{nd} / 3 \mathrm{rd}$ & m3 & 36 & $65 \%$ & $23 \%$ & 5.736 & * \\
\hline $1 \mathrm{st}$ & m4 & 36 & $67 \%$ & 5 th & m4 & 29 & $53 \%$ & $-14 \%$ & 2.199 & \\
\hline 5 th & m5 & 17 & $31 \%$ & 8th & m5 & 12 & $22 \%$ & $-10 \%$ & 1.303 & \\
\hline 2nd & m6 & 35 & $65 \%$ & $1 \mathrm{st}$ & m6 & 40 & $73 \%$ & $8 \%$ & 0.795 & \\
\hline 6th & m7 & 16 & $30 \%$ & 4th & m7 & 31 & $56 \%$ & $27 \%$ & 7.940 & $* *$ \\
\hline 8th & m8 & 10 & $19 \%$ & 6th & m8 & 17 & $31 \%$ & $12 \%$ & 2.245 & \\
\hline 9th & mOT & 4 & $7 \%$ & 9th & mOT & 7 & $13 \%$ & $5 \%$ & 0.850 & \\
\hline
\end{tabular}


Table 13 Assignment of statements from open-ended question on inhibitors to four inhibitor domains

\begin{tabular}{lll}
\hline Inhibitor domain & \# statements & $\%$ statements \\
\hline Business & 47 & $38 \%$ \\
Organisational & 27 & $22 \%$ \\
Technological & 33 & $26 \%$ \\
Industrial & 18 & $14 \%$ \\
All & 125 & $100 \%$ \\
\hline
\end{tabular}

\section{Discussion}

Large enterprises (LEs) show higher levels of interest and engagement in IoT application development than SMEs. The limited financial and human resources of SMEs, which hinder R\&D activities, might explain this result (Hausman 2005; Massa and Testa 2008; Laperche and Liu 2013). SMEs focus strongly on customers (Scozzi et al. 2005). In combination with the difficulty of predicting demand for and revenues of potential customer-oriented IoT applications, the strong focus of SMEs on customers does not have a positive impact on their levels of interest and engagement. However, SMEs are more flexible and can adapt quickly to changes in technologies or markets (Scozzi et al. 2005). Owing to this innovation advantage, SMEs could be expected to be more experienced in developing or deploying IoT applications.

The relatively high levels of interest and engagement in IoT application development and deployment reported in the survey may be ascribed to a selection bias, in that enterprises interested in deploying IoT applications are more likely to participate in the survey. The results in "Interest and engagement" section show that LEs have a higher interest and are more engaged in IoT application development than SMEs. The sample contains larger share of participants working in LEs than can be expected from the target population. A total of 33\% of the employees in the Swiss MEM industries work in LEs (Swissmem 2016). By contrast, $45 \%$ of the survey participants work in LEs. The larger share of participants from LEs could be an indicator of selection bias. Apart from that, selection bias is hardly measurable.

The open-ended and the close-ended questions on motivators delivered consistent results. The top motivator from the responses to the close-ended question is monitoring product state and usage for predictive maintenance and repair (m6). The highest number of statements from the open-ended question were indeed assigned to the marketing and sales activity segment. However, most statements assigned to this activity segment are vague and not very specific. A wide range of statements could thus be assigned to this segment. The activity segment that follows is service and aftersales. The statements belonging to this segment are more specific and often mention predictive maintenance. A few of the answers to the open-ended question cannot be assigned to an activity segment.

Table 14 Ranking of inhibitor domains ( $N=89$ )

\begin{tabular}{lllllllll}
\hline $\begin{array}{l}\text { Rank by score } \\
* * * \\
(p<0.001)\end{array}$ & Inhibitor domain & Ranking score & Ranking score \% & \# 1st & \# 2nd & \# 3rd & \# 4th & \# total \\
\hline 1st & Business & 267 & $100 \%$ & 34 & 29 & 18 & 8 & 89 \\
2nd & Organisational & 235 & $88 \%$ & 28 & 22 & 18 & 21 & 89 \\
3rd & Technological & 198 & $74 \%$ & 13 & 21 & 28 & 27 & 89 \\
4th & Industrial & 190 & $71 \%$ & 14 & 17 & 25 & 33 & 89 \\
\hline
\end{tabular}


Table 15 Ranking of inhibitors based on ranking scores of all four inhibitor domains $(N=89)$

\begin{tabular}{|c|c|c|c|c|c|}
\hline $\begin{array}{l}\text { Rank by score } \\
* * *(p<0.001)\end{array}$ & Inhibitor ID & Ranking score & \# selections & avg score per selection & avg score per participants \\
\hline $1 s t$ & 01 & 377 & 51 & 7.39 & 4.24 \\
\hline 2nd & 05 & 309 & 46 & 6.72 & 3.47 \\
\hline $3 r d$ & 07 & 231 & 37 & 6.24 & 2.60 \\
\hline 4 th & ०4 & 191 & 30 & 6.37 & 2.15 \\
\hline 5 th & 06 & 184 & 31 & 5.94 & 2.07 \\
\hline 6th & 02 & 149 & 22 & 6.77 & 1.67 \\
\hline 7th & 03 & 140 & 23 & 6.09 & 1.57 \\
\hline 8th & oNA & 56 & 7 & 8.00 & 0.63 \\
\hline $\begin{array}{l}\text { Rank by score } \\
* * *(p<0.001)\end{array}$ & Inhibitor ID & Ranking score & \# selections & avg score per selection & avg score per participants \\
\hline $1 \mathrm{st}$ & b1 & 265 & 38 & 6.97 & 2.98 \\
\hline 2nd & b5 & 261 & 39 & 6.69 & 2.93 \\
\hline $3 r d$ & b3 & 224 & 32 & 7.00 & 2.52 \\
\hline 4 th & b4 & 219 & 32 & 6.84 & 2.46 \\
\hline 5 th & b2 & 213 & 31 & 6.87 & 2.39 \\
\hline 6th & b7 & 146 & 24 & 6.08 & 1.64 \\
\hline 7th & b6 & 138 & 22 & 6.27 & 1.55 \\
\hline 8th & bNA & 64 & 8 & 8.00 & 0.72 \\
\hline $\begin{array}{l}\text { Rank by score } \\
* * *(p<0.001)\end{array}$ & Inhibitor ID & Ranking score & \# selections & avg score per selection & avg score per participants \\
\hline $1 \mathrm{st}$ & t3 & 385 & 40 & 9.63 & 4.33 \\
\hline 2nd & $\mathrm{t} 2$ & 351 & 35 & 10.03 & 3.94 \\
\hline $3 r d$ & $\mathrm{t} 1$ & 320 & 32 & 10.00 & 3.60 \\
\hline 4 th & t9 & 261 & 30 & 8.70 & 2.93 \\
\hline 5 th & t4 & 248 & 26 & 9.54 & 2.79 \\
\hline 6th & t7 & 212 & 24 & 8.83 & 2.38 \\
\hline 7th & t6 & 200 & 22 & 9.09 & 2.25 \\
\hline 8th & tNA & 99 & 9 & 11.00 & 1.11 \\
\hline 9th & t8 & 98 & 12 & 8.17 & 1.10 \\
\hline 10th & $\mathrm{t} 10$ & 96 & 12 & 8.00 & 1.08 \\
\hline 11th & t5 & 83 & 11 & 7.55 & 0.93 \\
\hline $\begin{array}{l}\text { Rank by score } \\
* * *(p<0.001)\end{array}$ & Inhibitor ID & Ranking score & \# selections & avg score per selection & avg score per participants \\
\hline 1st & ¡1 & 230 & 41 & 5.61 & 2.58 \\
\hline 2nd & i2 & 175 & 34 & 5.15 & 1.97 \\
\hline $3 r d$ & i5 & 159 & 31 & 5.13 & 1.79 \\
\hline 4th & i4 & 129 & 25 & 5.16 & 1.45 \\
\hline 5 th & iNA & 90 & 15 & 6.00 & 1.01 \\
\hline 6th & i3 & 74 & 16 & 4.63 & 0.83 \\
\hline
\end{tabular}

This could indicate that the value-chain model is not conceptually suitable for capturing motivators and expected added value, which is not the case. Most of these answers do not cover motivators or expected added value at all. A few are extrinsic motivators such as "this is the future", "we cannot ignore this trend", or "market pressure", which probably do not lead to a lasting engagement in IoT application development.

The results of the open-ended question on inhibitors are aligned with the finding from the close-ended questions that business inhibitors are the most challenging. The result related to the second-ranked inhibitor domain from the open-ended question does not 
align with the result obtained from the close-ended question. Participants answered the open-ended question before being presented the inhibitor domains and the full set of inhibitors. An insight from informal interviews with industry representatives is that the perception of IoT is technology-dominated. This could explain why inhibitors stated in response to the open-ended question are more technology-oriented. After being confronted with all inhibitor domains and the entire collection of inhibitors, the participants may reassess their opinion.

The results obtained in study show that business and organisational inhibitors hinder the realisation of IoT applications decisively and, therefore, hinder innovations based on IoT applications. This insight is not well represented in extant academic literature. The literature identifies challenges mainly in the technological or industrial domain (Atzori et al. 2010; Bandyopadhyay and Sen 2011; Khan et al. 2012; Sundmaeker et al. 2010; Miorandi et al. 2012) and considers the realisation of the IoT as the application of a certain technology (Lee and Lee 2015). Of course, the technological and industrial challenges outlined in existing literature must be solved to facilitate the development of IoT applications. However, the landscape of existing and economic IoT technology available in the market is already well developed. Consequently, researchers should focus increasingly on the business and organisational aspects of IoT application development and deployment.

There are a few limitations of the present study. The sample population was created through non-random convenience sampling. In addition, the results of the survey may not be replicable. While we recognise the downside of non-random sampling, this sampling method was selected from the viewpoint of practicality considering the study duration, resources at hand, and availability of the subjects. Although we cannot effectively comment on the parameters of the entire Swiss population or the industrial manufacturing enterprises of other nations, the results of the survey do provide meaningful insights about enterprises already interested or engaged in IoT. Moreover, it can be argued that the selection bias in non-random sampling is unlikely to have any effect on the sections pertaining to motivators and inhibitors. For example, enterprises that encounter technological challenges are not more likely to participate in the survey than those who encounter business challenges. Thus, apart from the results related to interest and activity, the results of all other sections of the survey should represent the trends among the industrial manufacturing enterprises who are already interested in IoT.

\section{Conclusions}

The results of this study show that among LEs in the Swiss MEM industries, the level of interest and engagement in developing IoT applications is generally higher than that among SMEs. The main motivation to develop IoT applications is implementing or improving service and aftersales activities in the value-chain of the enterprises by offering predictive product maintenance, for example. Four domains that covered exhaustively the inhibitors that hinder the development and deployment of IoT applications were identified from the literature: business, organisational, technological and industrial. Business and organisational inhibitors proved to be more relevant than technological and industrial ones. The authors identified business inhibitors, such as insufficient information to predict demand and revenues, resulting in high uncertainty and issues with monetisation under current business model, to be the most challenging ones. The 
domain of organisational inhibitors tied in second with relevant inhibitors such as lack of clear digital operations vision/strategy and lack of in-house expertise or skills. The most relevant technological inhibitors were difficulties related to interoperability with internal or external systems and difficulties in selecting enabling technologies to realise IoT applications. The industrial domain of inhibitors was found to be the least challenging with inhibitors such as undefined regulations and laws around customer privacy and data collection.

The approach of addressing exhaustively the motivators and inhibitors related to the development and deployment of IoT applications and comparing their relevance led to the insight that innovation for the IoT is not only about developing technology and overcoming privacy regulations, as is often discussed in academic literature, but also about developing and deploying successful IoT applications. The challenges relevant to this end at the enterprise level are not mainly about technology or regulations but about business and enterprise organisation. Business as well as enterprise organisation are driven by human behaviour and, therefore, deserve the increased attention of non-technical research fields, as is happening already in the field of innovation management (e.g. IoT business models). The potential of IoT applications in industrial manufacturing enterprises is not yet fully exploited. The extended value-chain model used in this study could help to identify novel IoT applications other than the well-known ones, such as predictive maintenance.

The results of this study imply that the identified inhibitors can be used by governments or industry associations interested in fostering IoT-based innovations or by enterprises operating in and innovating during the era of technology-driven digital transformation to refine policy and decision-making. Especially, governments and industry associations can define their supportive role for a future digital economy - as proposed by Hanna (2018) based on the learnings gained from this study. Two possible directions for future work can be derived from this study. The first is research on the tools and methods to overcome the inhibitors identified herein. The unpredictability of demand and revenues and the corresponding high degree of uncertainty could be addressed by using agile development methods, which facilitate rapid incorporation of user feedback. The challenge associated with that approach is managing the different paces of iteration cycles for hardware and software development. To help enterprises to overcome the lack of in-house expertise and skills, methods that allow organisations to acquire new knowledge quickly must be investigated. Second, the extended value-chain model can be investigated as a tool not only for allocating motivators but also for systematically searching for novel IoT applications along the entire value-chain.

\section{Methods}

\section{General approach}

The design of our empirical study is based on the sequential explorative research design described in Teddlie and Tashakkori (2006). This approach is favoured because academic literature covering the motivators and inhibitors of the development and deployment of IoT applications integrally is non-existent, and the possible range of results must be defined first. Two main working steps were taken to answer the RQs. First, the literature was reviewed to collect a broad spectrum of possible motivators and inhibitors of IoT application development and deployment and to develop a conceptual model 
which allows us to cover the inhibitors and motivators exhaustively. Second, based on the first step, a survey was designed and used to collect quantitative data for validating and measuring the relevance of the identified motivators and inhibitors and to test the formulated hypotheses.

\section{Data measurement}

A structured survey questionnaire containing four sections relevant to this study was designed and deployed: demographics, interest and engagement, motivators and inhibitors. The questions were designed to cover a wide range of answers because this work is an explorative empirical study on the topic, and the aim is to provide a general overview. Most questions were close-ended, except for the first question in the section pertaining to motivators and inhibitors. There, an open-ended question was used to allow participants to mention motivators and inhibitors without being biased by the answer options of the close-ended questions. The statements from the open-ended questions were coded manually into categories. Participants with no intentions to develop IoT applications (Table 5, no interest and no plans) were not asked to provide any answers on inhibitors because their insights were not expected to be valuable. In the section pertaining to interest and engagement, participants were asked to select the statement best describing their situation (single option selection). The close-ended question on motivators presented a set

Table 16 Participants' demographic profile

\begin{tabular}{|c|c|c|c|}
\hline Measure & Items & \# selections & $\%$ of $N=109$ \\
\hline \multirow[t]{5}{*}{ Title } & Executive & 36 & $33 \%$ \\
\hline & Department head & 29 & $27 \%$ \\
\hline & Staff & 23 & $21 \%$ \\
\hline & Unit head & 12 & $11 \%$ \\
\hline & Other & 9 & $8 \%$ \\
\hline \multirow[t]{8}{*}{ Functional area } & Management & 31 & $28 \%$ \\
\hline & Research and development & 34 & $31 \%$ \\
\hline & Information technology & 6 & $6 \%$ \\
\hline & Production & 5 & $5 \%$ \\
\hline & Quality engineering & 2 & $2 \%$ \\
\hline & Marketing and communication & 4 & $4 \%$ \\
\hline & Sales & 10 & $9 \%$ \\
\hline & Other & 17 & $16 \%$ \\
\hline \multirow[t]{6}{*}{ MEM industry domain } & Mechanical engineering & 34 & $41 \%$ \\
\hline & Electrical engineering/electronics & 24 & $29 \%$ \\
\hline & Precision instruments, apparatus and devices & 16 & $20 \%$ \\
\hline & Metals & 6 & $7 \%$ \\
\hline & Vehicles & 2 & $2 \%$ \\
\hline & Other & 27 & $33 \%$ \\
\hline \multirow[t]{6}{*}{ Product/service category ${ }^{a}$} & Power engineering transmission & 21 & $19 \%$ \\
\hline & Assembly and factory automation & 17 & $16 \%$ \\
\hline & Machine tools and manufacturing technology & 16 & $15 \%$ \\
\hline & Process engineering equipment & 15 & $14 \%$ \\
\hline & Precision tools & 11 & $10 \%$ \\
\hline & Remaining/other & 139 & $128 \%$ \\
\hline
\end{tabular}

${ }^{\mathrm{a}}$ Multiple selections allowed 
of motivators to the participants from which they could select multiple options. The relevance of a motivator was determined based on its overall selection frequency. In the section on inhibitors, participants were asked to select the relevant inhibitors and rank the selected ones. For the inhibitor domains, participants were asked to state the rank of each domain. The overall rank of an inhibitor or domain was calculated based on the ranking score (Hillmer 2017).

\section{Sample}

The target population of the survey comprised small-, medium- and large-sized enterprises from the MEM industries in Switzerland. The estimated size of the target population was 4000 enterprises (Swissmem 2016). The survey was accessible online between 21 February 2017 and 13 April 2017, and it was available in the three languages, namely, English, German, and French. To limit survey access to the target population, the survey was distributed through organisations related closely to the MEM industries. Links to the survey were shared through newsletters or mailing lists of the organisations, for example, INNOVATION NET WORK, SWISS ENGINEERING and INDUSTRIE2025. In addition, the online survey was distributed directly to members of the Zurich IoT Meetup Group and members of SWISSMEM.

Non-probability, convenience sampling was used to generate the sample. The number of complete survey responses and the resulting sample size of the study amounted to 109 enterprises. The enterprises ranged in size up to 350,000 full-time employees (FTEs) $(M=6913, M d n=220, \mathrm{SD}=37867)$. Of all enterprises, $55 \%$ were SMEs with up to 250 FTEs $(M=81, M d n=215$, SD $=81)$. Forty-five percent of the enterprises with over 250 employees were LEs $(M=15278, M d n=1500, \mathrm{SD}=55646)$. More than $20 \%$ of SMEs did not have a research and development (R\&D) department, compared to only $2 \%$ of the LEs. On average, there were 15 FTEs in the R\&D departments of the SMEs. LEs had larger R\&D departments with an average of 600 FTEs. More than $70 \%$ of the survey respondents reported that their positions were at the executive or managerial level (Table 16). The majority of the respondents worked in $R \& D(31 \%)$ or management (28\%).

\footnotetext{
Abbreviations

FTE: Full-time employees; H: Hypotheses; ICT: Information and communication technology; loT: Internet of things; LEs: Large enterprises; MEM: Metal, electrical, and machine; RQ: Research question; R\&D: Research and development; SMEs: Small- and medium-sized enterprises

Funding

This research project is funded by ETH Zurich (federally funded) and ETH Zurich Foundation. The ETH Zurich Foundation is an independent, non-profit organisation under private law with the aim of promoting teaching and research at ETH Zurich. The ETH Zurich Foundation awards funds to selected projects within the key strategic areas set by the ETH Zurich
} Executive Board.

Availability of data and materials

The survey questionnaire supporting the conclusions of this article is included in the additional files supplied with the article. The data supporting the conclusions of this article will not be shared owing to confidentiality agreements with the participating enterprises.

\section{Authors' contributions}

$\mathrm{TBH}$ is the main author of the article and is responsible for the conceptual architecture, data evaluation, conclusions and writing. JH helped with the questionnaire design and operative execution of the survey. MM co-designed the conceptual architecture. All authors reviewed and approved the final manuscript. 


\section{Publisher's Note}

Springer Nature remains neutral with regard to jurisdictional claims in published maps and institutional affiliations.

\section{Author details}

${ }^{1}$ ETH Zurich, Product Development Group Zurich, Leonhardstrasse 21, 8092 Zurich, Switzerland. ${ }^{2}$ University of Zurich, Rämistrasse 71, 8006 Zurich, Switzerland.

Received: 19 April 2018 Accepted: 23 August 2018

Published online: 25 September 2018

\section{References}

Adrodegari, F., Alghisi, A., Saccani, N. (2014). Towards usage-oriented business models: an assessment of European capital goods manufacturers, In Proceeding of 21st EurOMA conference, Palermo (ITA).

Ashton, K. (2009). That "internet of things" thing. RFiD Journal, 22(7), 97-114. http://www.itrco.jp/libraries/RFIDjournalThatInternetofThingsThing.pdf. Accessed 14 June 2016.

Atzori, L., lera, A., Morabito, G. (2010). The Internet of Things: a survey. Computer Networks, 54(15), 2787-2805. https://doi. org/10.1016/j.comnet.2010.05.010. Accessed 8 June 2015.

Bandyopadhyay, D., \& Sen, J. (2011). Internet of Things: applications and challenges in technology and standardization. Wireless Personal Communications, 58(1), 49-69. https://doi.org/10.1007/s11277-011-0288-5. Accessed 27 Sep 2016.

Brynjolfsson, E., \& McAfee, A. (2014). The second machine age: work, progress, and prosperity in a time of brilliant technologies. New York: Norton.

Burton, B., \& Walker, M.J. (2015). Hype cycle for emerging technologies. Retrieved October 13, 2016, from https://www. gartner.com/doc/3100227. Accessed 13 Oct 2016.

Curran, C., Puthiyamadam, T., Sviokla, J., Verweij, G. (2015). 2015 Global Digital IQ Survey: Lessons from digital leaders. Technical Report.PwC. https://www.pwc.ch/de/publications/2016/digital_iq_survey_2015.pdf. Accessed 7 Aug 2017.

Dijkman, R., Sprenkels, B., Peeters, T., Janssen, A. (2015). Business models for the Internet of Things. International Journal of Information Management, 35(6), 672-678. http://linkinghub.elsevier.com/retrieve/pii/S0268401215000766.

Fleisch, E., Weinberger, M., Wortmann, F. (2015). Business models and the Internet of Things (extended abstract), (pp. 6-10): Springer International Publishing, Cham. https://doi.org/10.1007/978-3-319-16546-2_2.

Geissbauer, R., Vedso, J., Schrauf, S. (2016). Industry 4.0: building the digital enterprise. Technical Report. https://www.pwc com/gx/en/industries/industries-4.0/landing-page/industry-4.0-building-your-digital-enterprise-april-2016.pdf.

Gepp, M., Gölzer, P., Grobholz, B. (2015). Engineer-to-order companies are reserved on adoption of current engineering trends - an empirical study, In 2015 IEEE International Conference on Industrial Engineering and Engineering Management (IEEM). https://doi.org/10.1109/IEEM.2015.7385902 (pp. 1525-1530).

Greif, H., Kühnis, N., Warnking, P. (2016). Digital transformation: How mature are Swiss SMEs? http://www.pwc.ch/en/ publications/2016/pwc_digital_transform_how_mature_are_swiss_smes_survey_16_en.pdf. Accessed 27 July 2017.

Gubbi, J., Buyya, R., Marusic, S., Palaniswami, M. (2013). Internet of Things (IoT): a vision, architectural elements, and future directions. Future Generation Computer Systems, 29(7), 1645-1660. https://doi.org/10.1016/j.future.2013.01.010.

Haller, S., Karnouskos, S., Schroth, C. (2009). The Internet of Things in an enterprise context, (pp. 14-28). Berlin. https://doi. org/10.1007/978-3-642-00985-3_2.

Hanna, N. (2018). A role for the state in the digital age. Journal of Innovation and Entrepreneurship, 7(1), 5. https://doi.org/ 10.1186/s13731-018-0086-3.

Hausman, A. (2005). Industrial Marketing Management. Innovativeness among small businesses: theory and propositions for future research, 34(8), 773-782. http://linkinghub.elsevier.com/retrieve/pii/S0019850105000039.

Heck, J. (2017). Creating mmentum and a positive long-term impact on the Innovation Capability of Swiss SMEs. PhD thesis, ETH, Zürich. https://doi.org/10.3929/ETHZ-A-010898455.

Heinis, T., Gomes Martinho, C., Meboldt, M. (2017). Fundamental challenges in developing Internet of Things applications for engineers and product designers, In DS 87-5 Proceedings of the 21st International Conference on Engineering Design (ICED 17) Vol 5: Design for X, Design to X, Vancouver, Canada, 21-25.08 (pp. 279-88).

Hillmer, B. (2017). Calculation of weighted ranking score. https://help.surveygizmo.com/help/rank-score.

Hsu, C.L., \& Lin, J.C.C. (2016). An empirical examination of consumer adoption of Internet of Things services: network externalities and concern for information privacy perspectives. Computers in Human Behavior, 62, 516-527. http:// linkinghub.elsevier.com/retrieve/pii/S0747563216302990.

Hui, G. (2014). So You Want to Build an Internet of Things Business: Harvard Business Review. https://hbr.org/2014/01/soyou-want-to-build-an-internet-of-things-business. Accessed 3 June 2016.

ICSA Labs (2017). IoT Security \& Privacy. Retrieved August 8, 2017, from https://www.icsalabs.com/technology-program/ iot-testing. Accessed: 8 Aug 2017.

loT Security Foundation (2017). loT is vast and has many security related issues - how do we go about addressing them? Retrieved August 8, 2017, from https://iotsecurityfoundation.org/working-groups/. Accessed 8 Aug 2017.

Kaleka, A. (2002). Resources and capabilities driving competitive advantage in export markets: guidelines for industrial exporters. Industrial Marketing Management, 31(3), 273-283. https://www.sciencedirect.com/science/article/pii/ S0019850100001486.

Khan, R., Khan, S.U., Zaheer, R., Khan, S. (2012). Future internet: the internet of things architecture, possible applications and key challenges, In 2012 10th International Conference on Frontiers of Information Technology. (pp. 257-260). IEEE. https://doi.org/10.1109/FIT.2012.53.

Kinkel, S., Rahn, J., Rieder, B., Lerch, C., Jäger, A. (2016). Digital-Vernetztes Denken In Der Produktion. Technical Report. https://doi.org/10.13140/RG.2.2.23720.37129.

Laperche, B., \& Liu, Z. (2013). SMEs and knowledge-capital formation in innovation networks: a review of literature. Journal of Innovation and Entrepreneurship, 2(1), 21. https://doi.org/10.1186/2192-5372-2-21.

Lee, I., \& Lee, K. (2015). The Internet of Things (IOT): applications, investments, and challenges for enterprises. Business Horizons, 58(4), 431-440. https://doi.org/10.1016/j.bushor.2015.03.008. 
Li, S., Da Xu, L., Zhao, S. (2014). The internet of things: a survey. Information Systems Frontiers, 17(2), 243-259.

Massa, S., \& Testa, S. (2008). Innovation and SMEs: misaligned perspectives and goals among entrepreneurs, academics, and policy makers. Technovation, 28(7), 393-407. https://doi.org/10.1016/j.technovation.2008.01.002. http:// linkinghub.elsevier.com/retrieve/pii/S0166497208000126.

McPhee, W., \& Wheeler, D. (2006). Making the case for the added-value chain. Strategy \& Leadership, 34(4), 39-46. https:// doi.org/10.1108/10878570610676873.

Miorandi, D., Sicari, S., De Pellegrini F., Chlamtac I. (2012). Internet of things: vision, applications and research challenges. Ad Hoc Networks, 10(7), 1497-1516. http://www.sciencedirect.com/science/article/pii/S1570870512000674.

Pech, RM. (2016). Achieving the innovative edge in technology, engineering design, and entrepreneurship. Journal of Innovation and Entrepreneurship, 5(1), 6. https://doi.org/10.1186/s13731-016-0035-y.

Perera, C., Liu, C.H., Jayawardena, S., Chen, M. (2014). A survey on Internet of Things from industrial market perspective. IEEE Access, 2, 1660-1679. https://doi.org/10.1109/ACCESS.2015.2389854.

Porter, M.E. (1985). Competitive advantage: Creating and sustaining, superior performance. New York: The Free Press.

Porter, M.E., \& Heppelmann, J.E. (2014). How smart, connected products are transforming competition. Harvard Business Review, 92(11), 64-88.

Porter, M.E., \& Heppelmann, J.E. (2015). How smart, connected products are transforming companies. Harvard Business Review, 93(10), 96-114.

Rajkumar, R.R., Lee, I., Sha, L., Stankovic, J. (2010). Cyber-physical systems: the next computing revolution, In Proceedings of the 47th Design Automation Conference. http://doi.acm.org/10.1145/1837274.1837461 (pp. 731-736). New York: ACM.

Raymond, L., Uwizeyemungu, S., Fabi, B., St-Pierre, J. (2018). IT capabilities for product innovation in SMEs: a configurational approach. Information Technology and Management, 19(1), 75-87. https://doi.org/10.1007/s10799-017-0276-X.

Russo, G., Marsigalia, B., Evangelista, F., Palmaccio, M., Maggioni, M. (2015). Exploring regulations and scope of the Internet of Things in contemporary companies: a first literature analysis. Journal of Innovation and Entrepreneurship, 4(1), 11. https://doi.org/10.1186/s13731-015-0025-5.

Saarikko, T., Westergren, U.H., Blomquist, T. (2017). The Internet of Things: are you ready for what's coming? Business Horizons, 60(5), 667-676. http://www.sciencedirect.com/science/article/pii/S000768131730068X?via\%3Dihub.

SAS Institute Inc (2016). Internet of Things visualise the impact. http://www.sas.com/de_ch/insights/big-data/internetof-things.html.

Schwab, K. (2015). The Fourth Industrial Revolution: what it means and how to respond. Foreign Affairs, https://www. foreignaffairs.com/articles/2015-12-12/fourth-industrial-revolution.

Scozzi, B., Garavelli, C., Crowston, K. (2005). Methods for modeling and supporting innovation processes in SMEs. European Journal of Innovation Management, 8(1), 120-137. http://www.emeraldinsight.com/doi.org/10.1108/ 14601060510578619.

Skinner, T. (2016). loT Outlook 2016. Retrieved August 9, 2017, from http://telecoms.com/intelligence/telecoms-com-iotoutlook-2016/.

Sundmaeker, H., Guillemin, P., Friess, P., Woelfflé, S. (2010). Vision and challenges for realising the Internet of Things. Cluster of European Research Projects on the Internet of Things. European Commision, 3(3), 34-36. https://doi.org/10. $2759 / 26127$.

Swissmem (2016). Panorama 2016 Zahlen und Fakten. Retrieved August 10, 2016, from https://www.swissmem.ch/ fileadmin/user_upload/Swissmem/Publikationen/Panorama/2016_Panorama_DE.pdf.

Teddlie, C., \& Tashakkori, A. (2006). A general typology of research designs featuring mixed methods. Research in the Schools, 13(1), 12-28.

Tobler, A., Grieder, P., Heck, R. (2013). Die Klaviatur für eine wettbewerbsfähige Schweizer MEM-Industrie. Zurich: McKinsey \& Company Schweiz. Retrieved July 11, 2016, from https://www.ub.unibas.ch/digi/a125/sachdok/2014/ BAU_1_6218937.pdf.

Twentyman, J., \& Swabey, P. (2015). Developing smart products. Tech. rep., The Economist Intelligence Unit. Retrieved July 25, 2016, from https://www.eiuperspectives.economist.com/sites/default/files/ElU-CognizantDevelopingsmartproducts.pdf.

Underwriters Laboratories (2016). UL launches cybersecurity assurance program. http://www.ul.com/newsroom/ pressreleases/ul-launches-cybersecurity-assurance-program/.

Weber, R.H. (2010). Internet of Things - new security and privacy challenges. Computer Law \& Security Review, 26(1), 23-30. https://doi.org/10.1016/j.clsr.2009.11.008.

Weiss, A., Schade, C., Riedl, M., Matt, D. (2016). Present and future of digitalization in South Tyrolean SMEs. Paper presented at the 1-14. Retrieved from https://search.proquest.com/docview/1860981961?accountid=27229. 